\title{
Climate-growth relationships of Qilian juniper Sabina przewalskii in the Anyemaqen Mountains, Tibet
}

\author{
Jian-feng Peng ${ }^{1}$, Xiao-hua Gou ${ }^{2, *}$, Fa-hu Chen ${ }^{2}$, Ke-yan Fang ${ }^{2}$ \\ ${ }^{1}$ College of environment and planning, Henan University, Kaifeng 475004, China \\ ${ }^{2}$ Center for Arid Environment and Paleoclimate Research (CAEP), MOE Key Laboratory of Western China's Environment \\ Systems, Lanzhou University, Lanzhou 730000, China
}

\begin{abstract}
Climate-growth relationships were investigated for 5 mountain slopes of the Anyemaqen Mountains on the northeastern Tibetan Plateau, using a tree-ring width network indicating the chronologies of 20 Qilian junipers Sabina przewalskii. Tree growth is mainly controlled by regional climate conditions, which are modulated by altitudinal factors. The tree growth patterns in this region were classified asccording to a west-east orientation. Temperature and precipitation from August to October of the previous year and May of the current year are the major limiting factors for most chronologies, as indicated by simple correlation analysis. In general, precipitation plays a more important role in governing tree growth than temperature, and tree rings in the east are more sensitive to precipitation than those in the west. Differences in the climate-growth relationship may be caused by varying climate conditions between the western and eastern Anyemaqen Mountains.
\end{abstract}

KEY WORDS: Tree ring · RPCA · Climate-growth relationship - Qilian juniper · Anyemaqen Mountains

Resale or republication not permitted without written consent of the publisher

\section{INTRODUCTION}

Owing to its enormous size and average altitudes of $>4000 \mathrm{~m}$ above sea level (a.s.l.), the Tibetan Plateau (TP) plays an important role in shaping the changes in the climate of the region (Böhner 2006, Duan et al. 2006). Therefore, numerous dendroclimatological studies have been conducted on the TP and in its vicinity (e.g. Zhang et al. 2003, Shao et al. 2004, Sheppard, et al. 2004, Liu et al. 2006, Li et al. 2008, Fang et al. 2009). Since it is necessary to study climate-growth relationships prior to reconstruction, many such studies have been conducted globally over different environmental gradients (Jacoby et al. 1996, Bräuning, 2001, Rigling et al. 2002, Rolland 2002, Esper \& Schweingruber 2004, Macias et al. 2004, Frank \& Esper 2005, Lara et al. 2005), as well as in varying micro-environments (Oberhuber \& Kofler 2000, Tardif et al. 2003, Neuwirth et al. 2004). Additionally, such climate-growth relationships can provide important information regarding the responses of forest systems to climate change (Esper \&
Schweingruber 2004). However, to our knowledge, limited information is available on the climate-growth relationship on the northeastern TP.

In the present study, 20 ring-width chronologies of Qilian junipers developed from 5 slopes of the Anyemaqen Mountains were statistically compared with regional climate conditions, in order to better understand tree-growth patterns and the climate-growth relationship for this region.

\section{MATERIALS AND METHODS}

\subsection{Study area}

The Anyemaqen Mountains, on the northeastern TP, are considered a transitional area between semi-humid and semi-arid zones (Fig. 1A). These mountains play an important role in modulating hydrological processes and are, therefore, regarded as the core area of the Natural Reserve for the headwaters of the Yellow River. 
In the region a continental climate dominates, with a short summer and long and cold winters. The mean annual temperature is from 0.5 to $3.9^{\circ} \mathrm{C}$, and the warmest mean monthly temperature is from 11.0 to $14.2^{\circ} \mathrm{C}$. In the study region annual precipitation is between 450 and $620 \mathrm{~mm}$, with from 56 to $62 \%$ of the annual precipitation falling during summer, possibly an indicator of a monsoonal climate (Wang 1988). Temperature and precipitation in the eastern Anyemaqen Mountains are higher than in the western part of the range, i.e. by about $4{ }^{\circ} \mathrm{C}$ in temperature and $18 \%$ in relative humidity.

Qilian juniper, one of the dominant species growing on the northeastern TP, is a cold- and drought-tolerant tree species. Pure Qilian juniper forests are mainly distributed on the southern slopes of the Anyemaqen Mountains, at altitudes ranging from 3400 to $3800 \mathrm{~m}$ a.s.l. (Fig. 1B). These are the southernmost and highest distribution limits of Qilian junipers (Qinghai Forest Editorial Committee 1993) and are areas sensitive to climate change.

\subsection{Chronology development}

A network of 20 Qilian juniper ring-width chronologies was collected along altitudinal gradients in the Anyemaqen Mountains, northeastern TP. Field work was carried out in June 2003 and July 2005. Sampling transects were located in Duoqing (DQ, Zhongtie forestry centre), Yangyu (YYA and YYC) and Hebei (HHB and HBS) (Fig. 1). There were 3 to 5 sampling sites on each sample slope. At each sampling site, 20 to 30 of the largest and presumably oldest trees were sampled. We selected trees that we suspected would be the most influenced by climatic signals, avoiding trees where there had been local disturbances or where trees were too close together and were therefore competing for resources. One or two cores per tree were extracted at approximately breast height (1.3 m) (Table 1).

All cores were mounted on slotted wooden boards and polished with different grades of sandpaper (a progressively finer grit), until annual rings could be easily distinguished (Stokes \& Smiley 1968). The ring widths were measured using a Velmex measuring system to $0.001 \mathrm{~mm}$. All tree-ring sequences measured were quality checked with the computer program COFECHA (Holmes 1983). Tree-ring cores of poor quality (e.g. fragmented, rotted, or not datable) were excluded. The ring-width series were standardized in order to remove biological trends, using conservative curves, e.g. a negative exponential curve or a straight line of any slope. For those series that could not be fitted using these curves, a cubic spline was used with a $50 \%$ frequency-response cutoff, equal to $67 \%$ of the series length. Tree-ring indices were calculated by the ratio between the raw ring width and the fitted values. Each ring-width series was standardized and averaged together to produce a mean stand chronology for each site, based on biweight robust estimation (Fritts 1976, Cook \& Kairiukstis 1990). In so doing, the standard and residual chronologies were produced using the program ARSTAN (Cook \& Holmes 1986). The results of ring-width chronology are dimensionless indices, with biological trends removed, and, thus, better represent the climatic signal (Cook \& Kairiukstis 1990).

In general, the sample size declines in the early portion of a tree-ring chronology; therefore, we used subsample signal strength (SSS) statistics (Wigley et al. 1984), with a threshold value of 0.80 , to evaluate the reliable time span of the final chronologies. The tree-ring chronology was further treated by variance stabilization due to the changing sample size (Meko et al. 1993).

\subsection{Climatic data}

Five meteorological stations (Maduo, Maqing, He'nan, Tongde and Xinghai), evenly distributed in the study area, were selected; for details see Table 2 and Fig. 1A.
Fig. 1. (A) Locations of sampling sites and some meteorological stations in the Anyemaqen Mountains, northeastern Tibetan Plateau. (B) Qilian juniper Sabina przewalskii distribution and sampling sites (DQ: Duoqing; YYA and YYC: Yangyu; HHB and HBS: Hebei) 
Table 1. Location details of sampling sites, time span of chronologies and numbers of cores considered in each chronology. a.s.l.: above sea level

\begin{tabular}{|c|c|c|c|c|c|c|c|c|}
\hline Site & $\begin{array}{l}\text { Long. } \\
\text { (E) }\end{array}$ & $\begin{array}{l}\text { Lat. } \\
\text { (N) }\end{array}$ & Slope aspect & $\begin{array}{c}\text { Site no. \& } \\
\text { abbrev. }\end{array}$ & $\begin{array}{l}\text { Altitude } \\
\text { (m a.s.l.) }\end{array}$ & Years & $\begin{array}{l}\text { No. of } \\
\text { years }\end{array}$ & $\begin{array}{l}\text { No. of } \\
\text { cores }\end{array}$ \\
\hline $\begin{array}{l}\text { Duoqing } \\
\text { (DQ) }\end{array}$ & $100^{\circ} 04^{\prime} 05^{\prime \prime}$ & $35^{\circ} 00^{\prime} 05^{\prime \prime}$ & $\mathrm{SE}$ & $\begin{array}{ll}1 & \mathrm{DQH} \\
2 & \mathrm{DQMH} \\
3 & \mathrm{DQML} \\
4 & \mathrm{DQL}\end{array}$ & $\begin{array}{l}3755 \\
3665 \\
3602 \\
3525\end{array}$ & $\begin{array}{l}1433-2004 \\
1298-2004 \\
1319-2004 \\
1088-2004\end{array}$ & $\begin{array}{l}572 \\
707 \\
686 \\
917\end{array}$ & $\begin{array}{l}50 \\
44 \\
44 \\
34\end{array}$ \\
\hline $\begin{array}{l}\text { Yangyu C } \\
\text { (YYC) }\end{array}$ & $100^{\circ} 20^{\prime} 10^{\prime \prime}$ & $34^{\circ} 48^{\prime} 01^{\prime \prime}$ & $\mathrm{S}$ & $\begin{array}{ll}5 & \text { YYCH } \\
6 & \text { YYCMH } \\
7 & \text { YYCML } \\
8 & \text { YYCL }\end{array}$ & $\begin{array}{l}3845 \\
3710 \\
3625 \\
3400\end{array}$ & $\begin{array}{l}1615-2002 \\
1686-2002 \\
1524-2002 \\
1390-2002\end{array}$ & $\begin{array}{l}388 \\
317 \\
479 \\
613\end{array}$ & $\begin{array}{l}26 \\
25 \\
41 \\
42\end{array}$ \\
\hline $\begin{array}{l}\text { Yangyu A } \\
\text { (YYA) }\end{array}$ & $100^{\circ} 20^{\prime} 20.5^{\prime \prime}$ & $34^{\circ} 47^{\prime} 13^{\prime \prime}$ & $\mathrm{E}$ & $\begin{array}{l}9 \text { YYAH } \\
10 \text { YYAM } \\
11 \text { YYAL }\end{array}$ & $\begin{array}{l}3480 \\
3430 \\
3390\end{array}$ & $\begin{array}{l}1385-2002 \\
1468-2002 \\
1609-2002\end{array}$ & $\begin{array}{l}618 \\
535 \\
394\end{array}$ & $\begin{array}{l}22 \\
19 \\
20\end{array}$ \\
\hline $\begin{array}{l}\text { Hebei S } \\
\text { (HBS) }\end{array}$ & $100^{\circ} 43^{\prime} 33^{\prime \prime}$ & $34^{\circ} 43^{\prime} 32^{\prime \prime}$ & $\begin{array}{c}\mathrm{S} \\
\text { (upper river \& } \\
\text { concave) }\end{array}$ & $\begin{array}{ll}12 & \text { HBSH } \\
13 & \text { HBSMH } \\
14 & \text { HBSML } \\
15 & \text { HBSL }\end{array}$ & $\begin{array}{l}3730 \\
3650 \\
3580 \\
3520\end{array}$ & $\begin{array}{l}1807-2004 \\
1778-2004 \\
1733-2004 \\
1498-2004\end{array}$ & $\begin{array}{l}198 \\
227 \\
262 \\
507\end{array}$ & $\begin{array}{l}29 \\
32 \\
27 \\
35\end{array}$ \\
\hline $\begin{array}{l}\text { Hebei E } \\
\text { (HHB) }\end{array}$ & $100^{\circ} 49^{\prime} 56^{\prime \prime}$ & $34^{\circ} 42^{\prime} 42^{\prime \prime}$ & SW & $\begin{array}{ll}16 & \text { HHBH } \\
17 & \text { HHBMH } \\
18 & \text { HHBM } \\
19 & \text { HHBML } \\
20 & \text { HHBL }\end{array}$ & $\begin{array}{l}3580 \\
3500 \\
3430 \\
3360 \\
3300\end{array}$ & $\begin{array}{l}1795-2004 \\
1789-2004 \\
1793-2004 \\
1817-2004 \\
1844-2004\end{array}$ & $\begin{array}{l}210 \\
216 \\
212 \\
188 \\
161\end{array}$ & $\begin{array}{l}24 \\
33 \\
30 \\
23 \\
34\end{array}$ \\
\hline
\end{tabular}

The mean annual temperature and precipitation (1960 to 2001) are shown in Fig. 2. For all of these stations, both peak precipitation and temperature are found in July; the mean monthly temperature is $>5^{\circ} \mathrm{C}$ and the mean monthly precipitation from May to September is $>40 \mathrm{~mm}$ (except at Maduo in May).

Correlation results of climatic records among 5 meteorological stations showed, with remarkable consistency, that correlations for both the mean monthly temperature and total monthly precipitation are $>98 \%$. However, correlation coefficients for mean annual temperature and total annual precipitation are not significant, with a correlation coefficient of -0.107 ( $p=0.499)$ for the mean annual temperature between Henan and Xinghai and of 0.251 ( $p=0.109$ ) for mean total precipitation between Henan and Maduo. Accordingly, in the present study, we utilized the climatic records from the meteorological stations in Maqing, Tongde and Xinghai.

\subsection{Rotated principal component analysis}

In order to explore the spatial patterns of the tree-ring network, rotated principal component analysis (RPCA) (Richman 1986, Cook et al. 2001) was employed on the 20 tree-ring chronologies over a common period from 1844 to 2002. RPCA analysis is used to maximize the spread of individual loadings and thus to produce more interpretable results (Richman 1986). The RPCA, determined by the Varimax method and a rigorous Monte Carlo test (Richman 1986, Cook et al. 2001), functioned as a form of cluster analysis in the present study. The series of PC scores over the chronology length represented the common growth patterns between them. The weight associated with each chronology conveyed information about the characteristic growth relationship between a specific site and the PC: the higher the weight, the closer the relationship (Legendre \& Legendre 1998, Zhang \& Hebda 2004).

To identify the influence of climatic factors on tree growth, standard ring-width chronologies were compared to temperature and precipitation records, using simple correlation analysis (Blasing et al. 1984)

Table 2. Location details and mean annual temperature and annual precipitation (1960 to 2001) of each meteorological station close to sampling sites

\begin{tabular}{|lrcccc|}
\hline $\begin{array}{l}\text { Meteorological } \\
\text { station }\end{array}$ & $\begin{array}{c}\text { Long. } \\
(\mathrm{E})\end{array}$ & $\begin{array}{c}\text { Lat. } \\
(\mathrm{N})\end{array}$ & $\begin{array}{c}\text { Altitude } \\
(\mathrm{m} \text { a.s.l. })\end{array}$ & $\begin{array}{c}\text { Temperature } \\
\left({ }^{\circ} \mathrm{C}\right)\end{array}$ & $\begin{array}{c}\text { Precipitation } \\
(\mathrm{mm})\end{array}$ \\
\hline Maduo (MD) & $98^{\circ} 13^{\prime}$ & $34^{\circ} 55^{\prime}$ & 4273.3 & -3.88 & 312.2 \\
Maqin (MQ) & $100^{\circ} 15^{\prime}$ & $34^{\circ} 28^{\prime}$ & 3720.0 & -0.53 & 506.4 \\
Henan (HN) & $101^{\circ} 36^{\prime}$ & $34^{\circ} 44^{\prime}$ & 3500.0 & 0.25 & 583.4 \\
Tongde (TD) & $100^{\circ} 39^{\prime}$ & $35^{\circ} 16^{\prime}$ & 3290.4 & 0.46 & 422.0 \\
Xinghai (XH) & $99^{\circ} 59^{\prime}$ & $35^{\circ} 35^{\prime}$ & 3324.3 & 1.23 & 350.6 \\
\hline
\end{tabular}



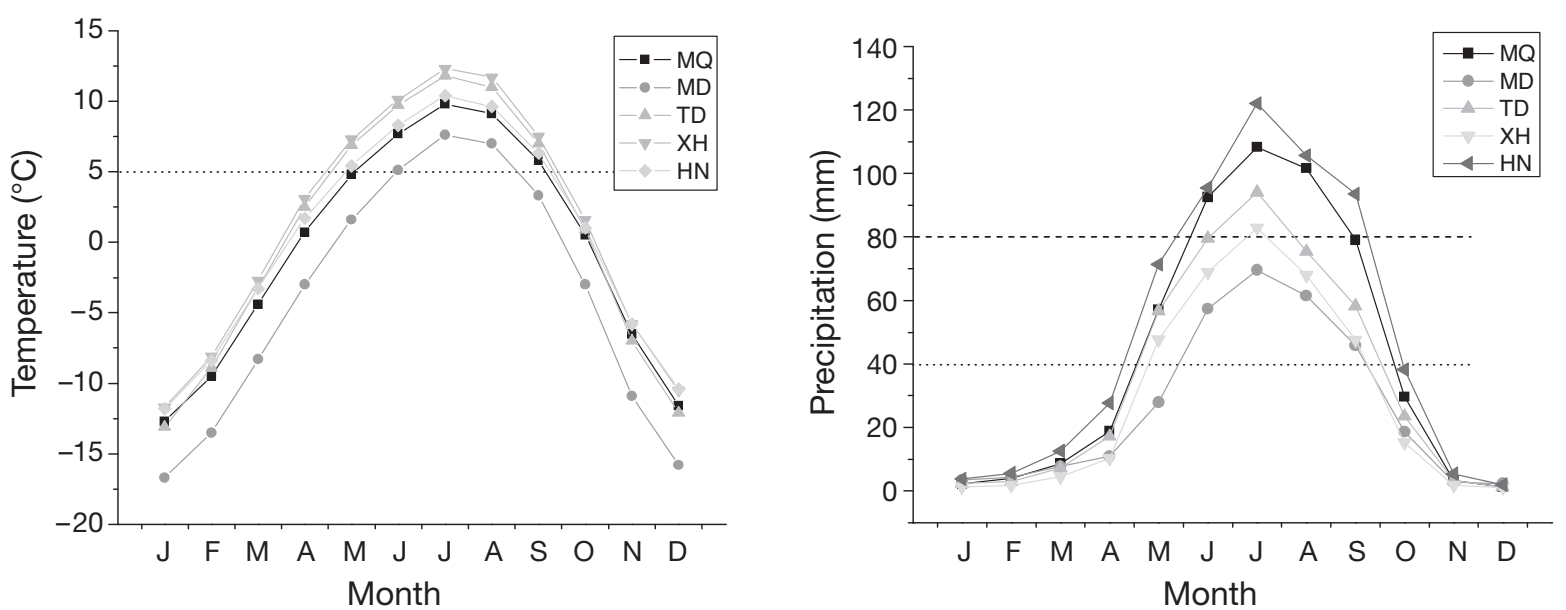

Fig. 2. Mean monthly temperatures $\left({ }^{\circ} \mathrm{C}\right.$ ) and total monthly precipitation (mm) averaged for the period from 1960 to 2001 , using records from each meteorological station in the Anyemaqen Mountains. Station abbreviations and details, see Table 2

and response function analysis by the programs DENDRO2002 (Biondi 2000) and PRECON Version 5.17 (Fritts 1998). The climate-growth relationships between ring width and monthly climate data were examined for the previous and current growing seasons, i.e. from July of the previous year to October of the current year. A positive (negative) value indicates that above-average growth is related to an above-average (belowaverage) value of the climate variable. All correlation functions and response function analyses were calculated for a common period (1960 to 2002) for the PC1 chronologies and the regional climatic records. The significance of the response coefficients was tested with a bootstrap method, which assesses the significance of the coefficients based on a large number of subsamples randomly extracted (Guiot 1991). Such random sampling and the subsequent calibration and verification of the climategrowth model were iterated 500 times with the program PRECON (Fritts 1994).

\section{RESULTS AND DISCUSSION}

\subsection{Characteristics of tree-ring chronologies}

Ring-width chronologies for Qilian junipers Sabina przewalskii were developed for each of the 20 sites on 5 slopes of the Anyemaqen Mountains (Fig. 1). As shown in Table 3, statistics for the high- altitude chronologies were lower than those for the low-altitude chronologies (see Table 1 for altitudes), except for the YYA slope. High signal-to-noise ratio (SNR) and expressed population (EPS) values in all chronologies (Table 3) imply strong climatic signals. But no clear spatial trends in chronological statistics were observed over the sampling area.

Table 3. Characteristics of standard chronologies. SSS: subsample signal strength; core: number of cores considered in each chronology; MS: mean sensitivity; SD: standard deviation; AC: first-order autocorrelation; SNR: signal-to-noise ratio; EPS: expressed population. Common time period for detrended series: 1900 to 2000

\begin{tabular}{|lcccccc|}
\hline Site no. \& ID & \multicolumn{2}{c}{ Year since } & \multicolumn{3}{c}{ Standard chronology } & \multicolumn{2}{c}{ Detrended series } \\
& SSS $>0.8($ core) & MS & SD & AC & SNR & EPS \\
\hline 1 DQH & $1551(12)$ & 0.128 & 0.179 & 0.601 & 10.221 & 0.911 \\
2 DQMH & $1329(9)$ & 0.150 & 0.219 & 0.647 & 11.012 & 0.917 \\
3 DQML & $1355(6)$ & 0.141 & 0.213 & 0.646 & 18.403 & 0.948 \\
4 DQL & $1178(7)$ & 0.220 & 0.276 & 0.537 & 7.530 & 0.883 \\
5 YYCH & $1836(8)$ & 0.136 & 0.209 & 0.641 & 5.682 & 0.850 \\
6 YYCMH & $1788(9)$ & 0.134 & 0.139 & 0.235 & 8.835 & 0.898 \\
7 YYCML & $1590(7)$ & 0.179 & 0.188 & 0.328 & 16.581 & 0.943 \\
8 YYCL & $1505(6)$ & 0.313 & 0.299 & 0.353 & 11.170 & 0.918 \\
9 YYAH & $1399(4)$ & 0.318 & 0.311 & 0.368 & 9.661 & 0.906 \\
10 YYAM & $1472(5)$ & 0.170 & 0.205 & 0.502 & 4.082 & 0.803 \\
11 YYAL & $1740(7)$ & 0.138 & 0.197 & 0.584 & 5.140 & 0.837 \\
12 HBSH & $1849(8)$ & 0.136 & 0.182 & 0.567 & 5.542 & 0.847 \\
13 HBSMH & $1802(9)$ & 0.108 & 0.162 & 0.598 & 7.912 & 0.888 \\
14 HBSML & $1811(9)$ & 0.108 & 0.162 & 0.662 & 7.043 & 0.876 \\
15 HBSL & $1740(10)$ & 0.173 & 0.190 & 0.331 & 9.242 & 0.902 \\
16 HHBH & $1827(7)$ & 0.169 & 0.198 & 0.387 & 3.856 & 0.794 \\
17 HHBMH & $1800(4)$ & 0.250 & 0.255 & 0.365 & 18.625 & 0.949 \\
18 HHBM & $1798(5)$ & 0.172 & 0.181 & 0.270 & 13.615 & 0.932 \\
19 HHBML & $1860(7)$ & 0.173 & 0.204 & 0.435 & 8.356 & 0.893 \\
20 HHBL & $1853(4)$ & 0.150 & 0.199 & 0.552 & 16.548 & 0.943 \\
\hline
\end{tabular}



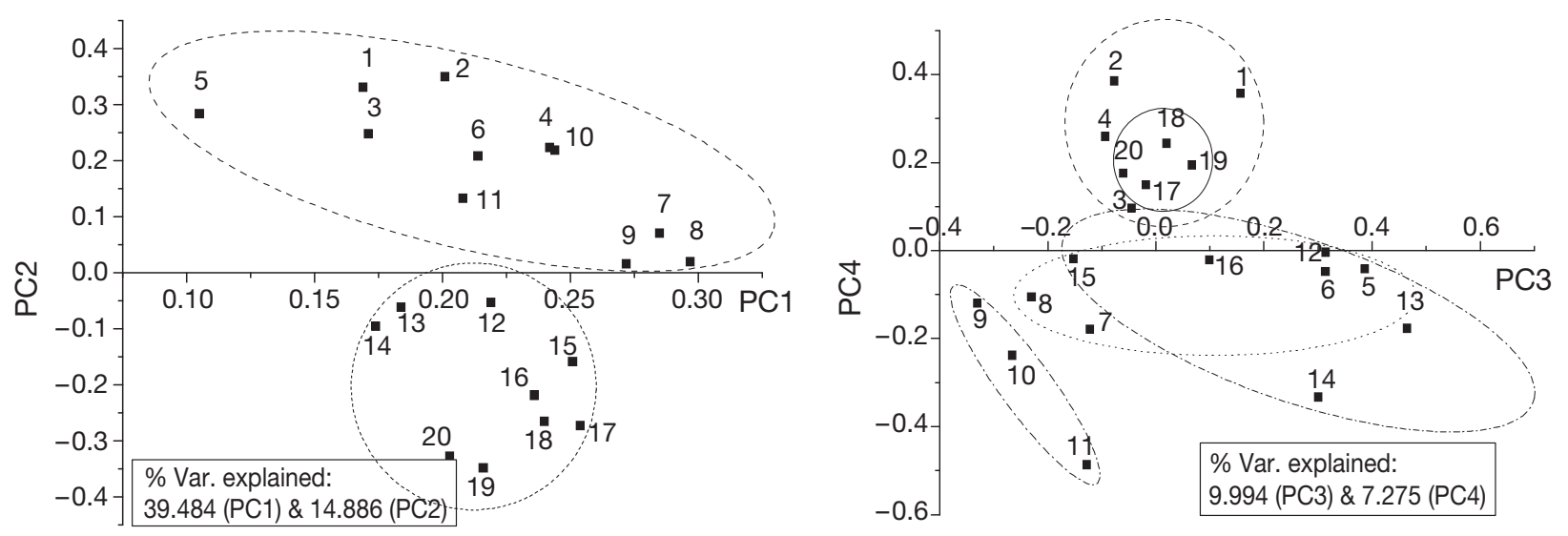

Fig. 3. Scatterplots of the loadings derived from each standard series of the 4 principal components (PCs). Site numbers, see Table 1

Most correlations among standard chronologies between mountain pairs are significant, with a mean correlation coefficient of 0.35 for all sites (minimum $\mathrm{r}=$ -0.179 , maximum $r=0.833$ ). The highest correlation between sites on a single slope occurred between the standard series in the westernmost area, with highest correlations $>0.8$ (YYCL-YYAH, $\mathrm{r}=0.833$; YYCLYYCML, $r=0.818$ ). Correlations between chronologies for the Duoqing (DQ) and eastern Hebei (HHB) sites are slightly lower (DQH-DQMH, $\mathrm{r}=0.798$; DQMHDQL, $\mathrm{r}=0.756$; YYAH-YYAM, $\mathrm{r}=0.700$; YYAMYYAL, $r=0.714$; HHBM-HHBML, $r=0.754$; HHBMLHHBL, $r=0.794)$. Negative correlations are seen for mountain pairs from the west vs. east (DQH-HHBL, $\mathrm{r}=-0.033$; YYCH-HBSL, $\mathrm{r}=-0.179$; YYCH-HHBMH and YYCH-HHBM, $\mathrm{r}=-0.053)$. The lower correlations tend to occur between chronologies at high altitudes at the westernmost sites (mainly between DQH and $\mathrm{YYCH}$ ), and some chronologies in the eastern study area (HBSML, HBSL, and all HHB chronologies), and higher correlations occur between chronologies at lower altitudes in the western study area and all chronologies in the eastern study area. Similar results related to altitude gradients have been described by Macias et al. (2004) for northern Fennoscandia. Macias proposed that the lower correlations could be due to the youngest and least replicated chronologies.

\subsection{Growth variations}

Principal component analysis (PCA) was used to explore similar growth patterns in 20 standard chronologies for a common period of time from 1844 to 2002. The first 2 principal components (PC) account for $54.4 \%$ of the total variance (Table 4). PC1, PC2, PC3 and PC4 explain 39.5, 14.9, 10.0 and $7.3 \%$ of the total variance, respectively. The loadings of PC1 are positive for all chronologies (Fig. 3), reflecting similar growth patterns at all of these sites. PC2 yields positive loadings over 11 chronologies in the western study region and negative loadings over 9 chronologies in the eastern area (Fig. 3), indicating a clear separation of the eastern and western chronologies. Thus, PC2 indicates a difference in tree growth between the eastern and western Anyemaqen Mountains. PC3 shows the effect of altitude in separating sites. Loadings change according to increasing altitude on YYC (Sites 5 to 8), YYA (Sites 9 to 11) and HBS (Sites 12 to 15) slopes. Apparently, this effect is due to the transformation of temperature and precipitation with increasing altitude. The distributions of PC4 in the scatterplot (Fig. 3) show that PC4 weighting coefficients of $\mathrm{DQ}$ and $\mathrm{HHB}$ sampling sites (except Site 16) are positive, while others are negative.

Table 4. Principal component analysis derived from 20 tree-ring standard chronologies. Common time period. 1844 to 2002

\begin{tabular}{|c|c|c|c|c|c|c|}
\hline \multirow{2}{*}{ Component } & \multicolumn{3}{|c|}{ Initial eigenvalues } & \multicolumn{3}{|c|}{ - Rotation sums of squared loadings } \\
\hline & Total & Percent of variance & Cumulative percent & Total & Percent of variance & Cumulative percent \\
\hline 1 & 7.897 & 39.484 & 39.484 & 4.401 & 22.006 & 22.006 \\
\hline 2 & 2.977 & 14.886 & 54.370 & 3.784 & 18.919 & 40.925 \\
\hline 3 & 1.999 & 9.994 & 64.365 & 3.048 & 15.240 & 56.165 \\
\hline 4 & 1.455 & 7.275 & 71.640 & 2.239 & 11.193 & 67.357 \\
\hline 5 & 1.330 & 6.652 & 78.292 & 2.187 & 10.934 & 78.292 \\
\hline
\end{tabular}



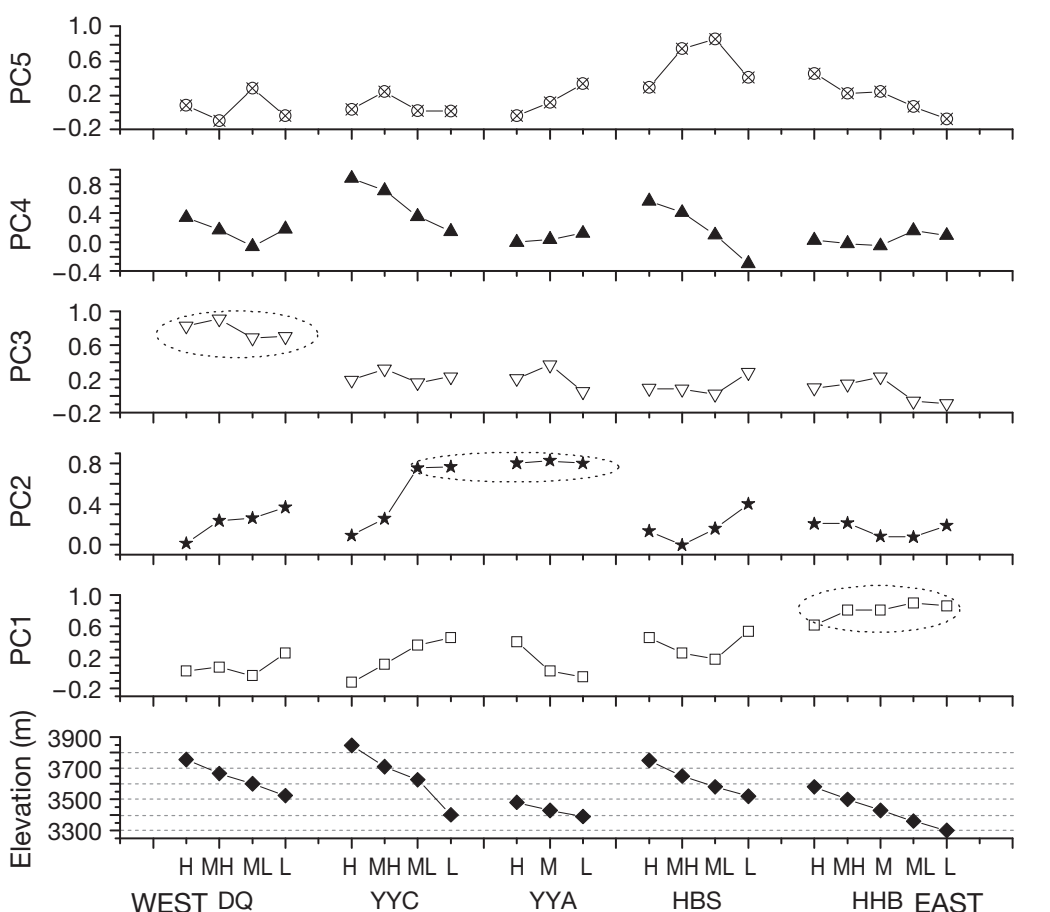

Fig. 4. Varimax loadings of the first 5 PCs for all 20 chronologies. Each point represents a single chronology, and each group, a slope
Fig. 5 shows PC1 scores derived from all standard chronologies in the reliable time period along a west-east gradient. The growth rate in younger trees is higher in the west than in the east. In addition, identical pointer years (low component scores for PC1) and the disagreement in low-frequency fluctuation (curves of the 31 yr running means) indicates that tree growth varies from site to site at both high and low frequencies. The most striking feature of the first PC is that there are more negative scores $(<-3)$ than positive scores $(>3)$ in the whole study area. The large number of negative scores indicates that below-average growth dominates throughout the study area; this also shows that acute events that drastically influence tree growth may occur frequently in the study area. Finally, in recent decades, a pattern of increased (decreased) growth has been observed in the west (east). Our interpretation is that, due to the warming trend in recent decades, melting glaciers have resulted in increased soil water content in the west, but intensified evaporation in the east has led to drier conditions.

\subsection{Climate-growth relationship}

RPCA based on Varimax rotation was used to produce more spatially interpretable loadings. As shown in Fig. 4, PC1, yielding the highest loadings over sites in the eastern Anyemaqen Mountains, is referred to as the 'eastern Anyemaqen factor' or 'low altitude factor'. PC2, including all YYA sites and the 2 lower sites on the YYC slope, with the lower-middle Anyemaqen loadings higher than those of the other slope samples, is called the 'middle Anyemaqen factor' or 'middle altitude factor'. Likewise, PC3 is termed the 'western Anyemaqen factor' or 'the higher altitude factor'. Similar to the spatial growth patterns indicated by PC2 and PC3, the first 3 PC patterns are also largely controlled by the differences between mountains and altitudes. Meanwhile, the variability within each PC factor, which might be related to a factor involving the slope, was not evident. In the area studies, climate data (Table 2) revealed that precipitation decreases from east to west (HN-MQ-MD or HN-TD-XH) in the Anyemaqen Mountains, which is consistent with the climate change gradient; this may be due to a decreasing gradient of monsoon conditions.

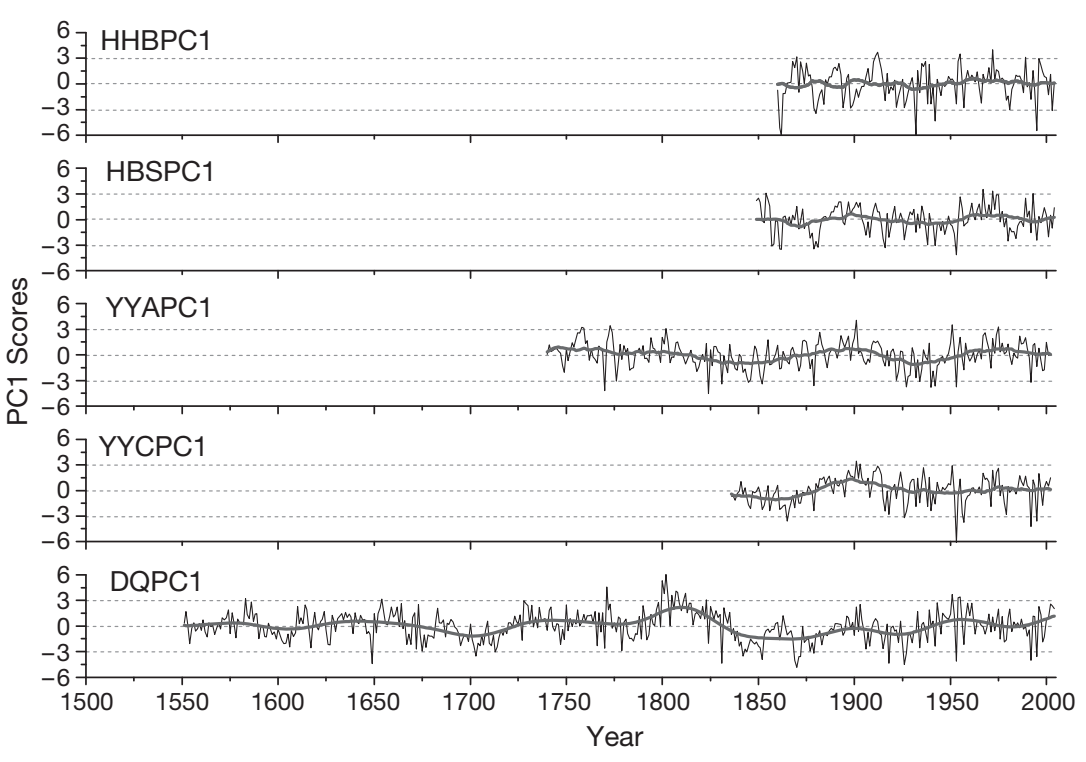

Fig. 5. PC1 scores derived from standard chronologies (subsample signal strength $>0.8$ ) on 5 slopes. Thick lines: 31 yr running means. Site abbreviations and details in Table 1 
study also showed that the radial growth of Qilian juniper at sites on a mountainous slope contains differing signals. The climate-growth correlation and response analyses were also conducted between the PC1 scores derived for the entire region and the chronologies on 3 slopes.

\subsubsection{Climate-growth response for the whole region}

The results of correlation analysis for the whole study region are shown in Fig. 6A, B (20PC1 plot). The most significant growth-limiting factors are the tem- perature and precipitation in May of the current year, with significant negative correlation to temperature and significant positive correlation to precipitation in the whole study area. Another significant period is August to October of the previous year, with significant positive correlation with total monthly precipitation. Generally, May to September is a warm and humid time of the year on the TP (Qinghai Forest Editorial Committee 1993). Fig. 2 shows that the mean monthly temperature during the period from May to September is $5^{\circ} \mathrm{C}$ above-and precipitation is $40 \mathrm{~mm}$ higher - than values for most of the weather stations
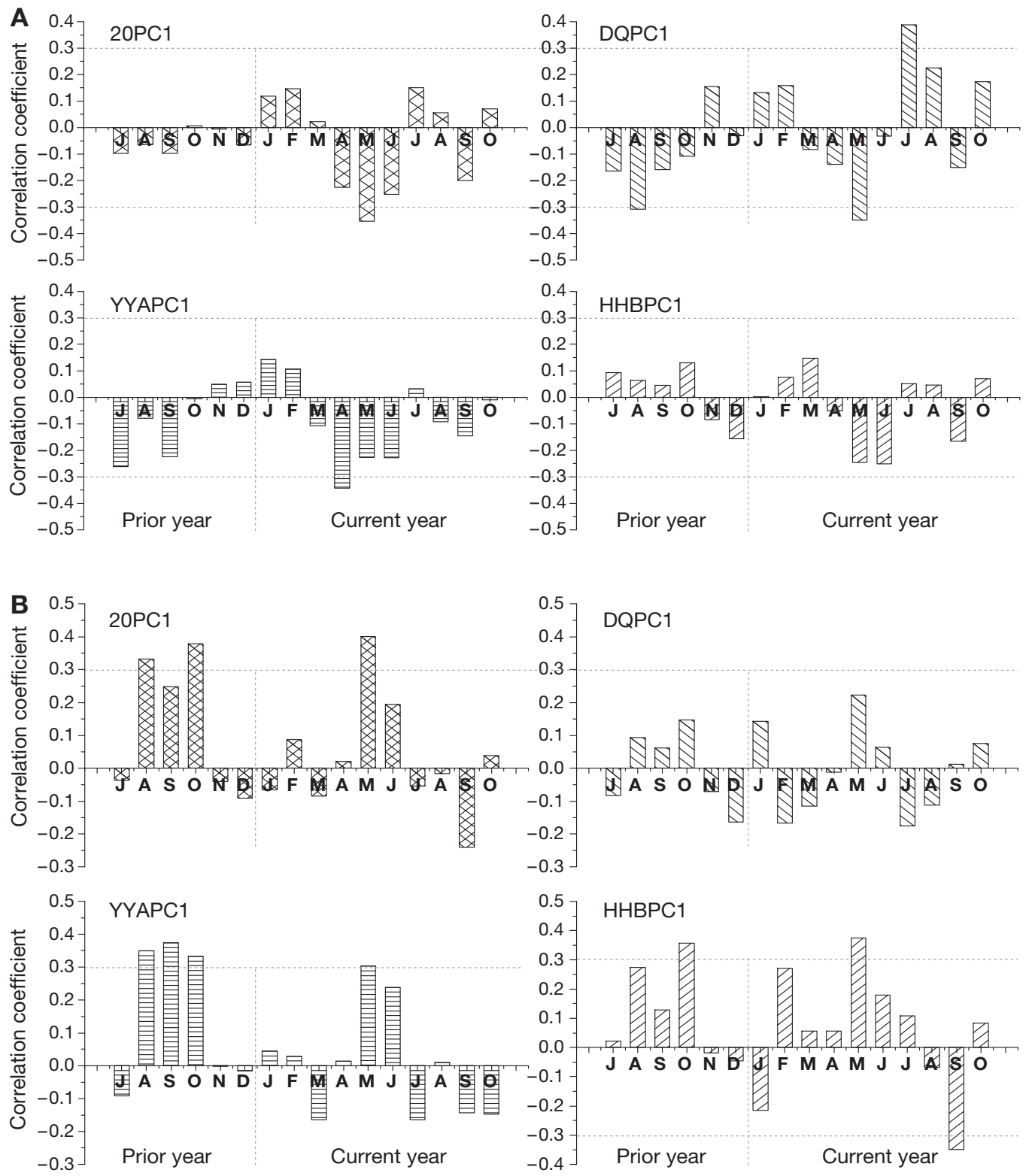

Fig. 6. Correlation of PC1 scores with (A) mean monthly temperature and (B) total monthly precipitation. Left panels in each graph: prior year; right panels in each graph: current year. Horizontal dashed lines: 95\% significant levels. 20PC1: PC1 from 20 chronologies (i.e. whole study area) 
nearby. Air temperature increases in May, and evaporation also generally increases in May on the TP, suggesting the beginning of the growing season. High precipitation during May has a positive effect on tree growth, since water is a requirement of photosynthesis, and also makes nutrients available to the trees from the surrounding environment. Similar results have been reported for the southern TP by Qin et al. (2003) and for the Delingha area of Qinghai by Shao et al. (2004).

Variances in the explained relationships were compared between the first PC for tree growth in the whole region and different climatic factors. The response function explains $70.2 \%$ of the total variance in the tree-ring growth $\mathrm{PC} 1$ for the whole region: 52\% is explained by temperature and precipitation together, and $18.2 \%$ is explained by growth in the previous year. However, 37.7 and $47.9 \%$ are explained by temperature and precipitation, respectively. In general, the combination of temperature and precipitation has a significant influence on tree growth; precipitation is more influential on tree growth than is temperature.

\subsubsection{Climate-growth relationships on 3 selected sampling slopes}

Three sampling slopes were selected to study various climate responses (Fig. 6). Tree growth on the DQ slope has a significant negative correlation with the temperature in May of the current year and August of the previous year, a significant positive correlation with the temperature in July and no significant correlation with precipitation.

Tree growth on the YYA sampling slope only has a significant negative correlation with the mean temperature in April of the current year. A significant negative correlation with precipitation, however, is observed in several months, including May of the current year and August to October of the previous year.

Tree growth on the HHB sampling slope has no significant correlation with mean temperature. Significant correlation is found between tree growth and precipitation in February and May of the current year and August and October of the previous year. There is also significant negative correlation with precipitation in September of the current year.

Apparently, the mean monthly temperature (e.g. current May and previous July to September) has a weaker influence on tree growth at eastern sampling sites, while the influence of precipitation on tree growth in May of the current year is stronger. The strongest influence of precipitation is found in August and October of the previous year at the YYA sampling sites. These differences in climate-growth correlations may be explained by the effect of mountain aspects, as supported by similar results obtained for the area near the Inn River (Tyrol, Austria) (Oberhuber \& Kofler 2000). Different slopes would modify temperature and precipitation levels, producing abundant precipitation at higher altitudes. Therefore, no significant correlation is found between precipitation and tree growth in DQ (southeast-facing); only temperature is influential for tree growth at this site due to its high altitude. Although YYA is located on a southeast-facing slope, it is situated in the upper area of a northward flowing river, in a semi-closed, lower narrow valley with a leeward slope, and a watershed is located on the southern side. In this case, tree growth was more sensitive to precipitation.

PC1 patterns of tree growth in relation to climatic factors on different sampling slopes show that total variances to tree growth derived from temperature and precipitation together are relatively high (DQ: 72.8\%; YYA: $68.6 \%$; HHB: $72.7 \%$ ). Growth variance explained by temperature has an increasing trend from east to west, while variance explained by precipitation decreases from east to west. Temperature is the factor that is most limiting to tree growth at the westernmost sampling sites (DQ), because a variance of $59.5 \%$ in growth by temperature outclassed the variance of $26.7 \%$ in growth by precipitation. Similar results have been reported by Kang et al. (1997) for the arid and semi-arid Dulan area of Qinghai and by Wang et al. (1982) and Liu et al. (2005) in the Qilian Mountains. Almost identical levels of variance are explained by temperature and precipitation on sampling slopes in the intermediate area (YYA), with 42.7 and 50.4\%, respectively, showing that temperature and precipitation influence tree growth equally in this area of the study region. In HHB, however, growth variance explained by temperature was less than that explained by precipitation: 22.3 and $52.0 \%$, respectively. In this case, it is obvious that precipitation is the most important factor influencing tree growth on most of the eastern sampling slopes.

\section{CONCLUSIONS}

Based on the tree ring-width chronologies of 20 Qilian junipers Sabina przewalskii, derived from 5 sampling slopes in the Anyemaqen Mountains, northeastern TP, some preliminary conclusions can be drawn:

(1) Scatterplots of principal component loadings indicate that the climate conditions of different mountains were more important in determining tree growth than altitudinal differences.

(2) Correlations between the first principal component $(\mathrm{PC} 1)$ and climatic factors reveal differences in radial growth along a west-east gradient in the study 
area. The combination of temperature and precipitation for May of the current year and August to October of the previous year are the major limiting factors for radial growth for the whole study area, especially precipitation in May (current) and August to October (previous).

(3) Climate response analyses show that precipitation was the most important factor influencing tree growth in the whole study area. However, tree ring widths were more limited by temperature in the western study area, radial growth was more limited by precipitation in the eastern Anyemaqen range, and an intermediate pattern was observed for the sites in between.

(4) The differing climate-growth relationships may be explained by the differences in their microenvironments.

Acknowledgements. This research was funded by the National Natural Science Foundation of China (NSFC) (No. 40971119), the Chinese NSFC Innovation Team Project (No. 40721061), and 100 Talents Program of the Chinese Academy of Sciences (No. 29O827B11). We sincerely thank many people for their help in the field (e.g. Drs. Z. D. Hou, Q. B. Zhang, J. B. Li and Y. Zhang).

\section{LITERATURE CITED}

Biondi F (2000) Are climate-tree growth relationships changing in north-central Idaho? Arct Antarct Alp Res 32: 111-116

Blasing TJ, Solomon AM, Duvick DN (1984) Response functions revisited. Tree-Ring Bull 44:1-15

Böhner J (2006) General climatic controls and topoclimatic variations in Central and High Asia. Boreas 35:279-295

Bräuning A (2001) Climate history of the Tibetan Plateau during the last 1000 years derived from a network of Juniper chronologies. Dendrochronologia 19:127-137

Cook ER, Holmes RL (1986) Users' manual for ARSTAN. Laboratory of Tree-Ring Research, University of Arizona, Tucson, AZ

Cook ER, Kairiukstis LA (1990) Methods of dendrochronology: applications in the environmental sciences. Kluwer, Dordrecht

Cook ER, Glitzenstein JS, Krusic JK, Harcombe PA (2001) Identifying functional groups of trees in west Gulf Coast (USA): a tree-ring approach. Ecol Appl 11:883-903

Duan K, Yao T, Thompson L (2006) Response of monsoon precipitation in the Himalayas to global warming. J Geophys Res 111:D19110. doi:10.1029/2006JD007084

Esper J, Schweingruber FH (2004) Large-scale treeline changes recorded in Siberia. Geophys Res Lett 31:L06202. doi:10.1029/2003GL019178

Fang K, Gou X, Chen F, Yang M and others (2009) Drought variations in the eastern part of Northwest China over the past two centuries: evidence from tree rings. Clim Res 38:129-135

> Frank D, Esper J (2005) Characterization and climate response patterns of a high-elevation, multi-species treering network in the European Alps. Dendrochronologia 22:107-121
Fritts HC (1976) Tree rings and climate. Academic Press, New York

Fritts HC (1994) Quick help for PRECON now called PRECONK Version 4.0. Dendrochronological Modeling, Tucson, AZ

Fritts HC (1998) Quick help for PRECONK, Version 5.17. Dendrochronological Modelling, Tucson, AZ

Guiot J (1991) The bootstrapped response function. Tree-Ring Bull 51:39-41

Holmes RL (1983) Computer-assisted quality control in treering dating and measurement. Tree-Ring Bull 43:69-78

Jacoby GC, Wiles G, D'Arrigo RD (1996) Alaskan dendroclimatic variations for the past 300 years along a north-south transect. Radiocarbon 35:235-248

Kang X, Graumlich LJ, Sheppard PR (1997) A 1835 tree-ring chronology and its preliminary analysis in Dulan region, Qinghai. Chin Sci Bull 42:1628-1631 (in Chinese)

Lara A, Villalba R, Wolodarsky-Franke A, Aravena JC, Luckman BH, Cuq E (2005) Spatial and temporal variation in Nothofagus pumilio growth at tree line along its latitudinal range $\left(35^{\circ} 40^{\prime}-55^{\circ} \mathrm{S}\right)$ in the Chilean Andes. J Biogeogr 32:879-893

Legendre P, Legendre L (1998) Numerical ecology. Elsevier Science B.V., Amsterdam

Li J, Cook ER, D'Arrigo R, Chen F, Gou X, Peng J, Huang J (2008) Common tree growth anomalies over the northeastern Tibetan Plateau during the last six centuries: implications for regional moisture change. Global Change Biol 14:2096-2107

Liu XH, Qin DH, Shao XM, Chen T, Ren JW (2005) Temperature variations recovered from tree-rings in the middle Qilian Mountain over the last millenium. Sci China Ser D 48:521-529

> Liu Y, An Z, Ma H, Cai Q and others (2006) Precipitation variation in the northeastern Tibetan Plateau recorded by the tree rings since $850 \mathrm{AD}$ and its relevance to the Northern Hemisphere temperature. Sci China Ser D 49:408-420

Macias M, Timonen M, Kirchhefer AJ, Lindholm M, Eronen M, Gutierrez E (2004) Growth variability of Scots pine (Pinus sylvestris) along a west-east gradient across northern Fennoscandia: a dendroclimatic approach. Arct Antarct Alp Res 36:565-574

> Meko DM, Cook ER, Stahle DW, Stockton CW, Hughes MK (1993) Spatial patterns of tree-growth anomalies in the United States and southeastern Canada. J Clim 6: 1773-1786

> Neuwirth B, Esper J, Schweingruber FH, Winiger M (2004) Site ecological differences to the climatic forcing of spruce pointer years from the Lötschental, Switzerland. Dendrochronologia 21:69-78

Oberhuber W, Kofler W (2000) Topographic influences on radial growth of Scots pine (Pinus sylvestris L.) at small spatial scales. Plant Ecol 146:229-238

Qin N, Shao X, Jin L, Wang Q, Zhu X, Wang Z, Li J (2003) Climate change over southern Qinghai Plateau in the past 500 years recorded in Sabina tibetica tree rings. Chin Sci Bull 48:2483-2487 (in Chinese)

Qinghai Forest Editorial Committee (1993) Forest in Qinghai Province. China Forestry Press, Beijing (in Chinese)

Richman MB (1986) Rotation of principal components. J Clim 6:293-335

Rigling A, Braker O, Schneiter G, Schweingruber FH (2002) Intra-annual tree-ring parameters indicating differences in drought stress of Pinus sylvestris forests within the EricoPinion in the Valais (Switzerland). Plant Ecol 163:105-121

> Rolland C (2002) Decreasing teleconnections with inter-site distance in monthly climatic data and tree-ring width net- 
works in a mountainous alpine area. Theor Appl Climatol 71:63-75

Shao X, Huang L, Liu H, Liang E, Fang X, Wang L (2004) Annual precipitation variation during the past 1000 years from tree rings in Delingha, Qinghai province, China. Sci China Ser D 34:145-153 (in Chinese)

Sheppard PR, Tarasov PE, Graumlich LJ, Heussner KU and others (2004) Annual precipitation since 515 BC reconstructed from living and fossil juniper growth of northeastern Qinghai Province, China. Clim Dyn 23:869-881

Stokes MA, Smiley TL (1968) An introduction to tree ring dating. The University of Chicago Press, Chicago, IL

Tardif J, Camarero JJ, Ribas M, Gutierrez E (2003) Spatiotemporal variability in tree growth in the Central Pyrenees: climatic and site influences. Ecol Monogr 73:241-257

Wang J (1988) The climate and physiognomy of Anymaqen

Editorial responsibility: Mauricio Lima,

Santiago, Chile
Mountains. J Glaciol Geocryol 10:6-7 (in Chinese)

Wang Y, Liu G, Zhang X, Li C (1982) The relationships between the tree rings of Sabina przewalskii Kom. and climate change of thousand years, glacier activity in Qilian Mountains. Chin Sci Bull 21:1316-1319 (in Chinese)

- Wigley L, Briffa KR, Jones PD (1984) On the average value of correlated time series, with applications in dendroclimatology and hydrometeorology. J Clim Appl Meteorol 23:201-213

Zhang Q, Hebda RJ (2004) Variation in radial growth patterns of Pseudotsuga menziesii on the central coast of British Columbia, Canada. Can J For Res 34:1946-1954

> Zhang Q, Cheng G, Yao T, Kang X, Huang J (2003) A 2326year tree-ring record of climate variability on the northeastern Qinghai-Tibetan Plateau. Geophys Res Lett 30: 1739. doi: 10.1029/2003GL017425

Submitted: March 24, 2009; Accepted: November 5, 2009 Proofs received from author(s): January 24, 2010 